"Low-risk effect: evidence, explanations and approaches to enhancing the performance of low-risk investment strategies"

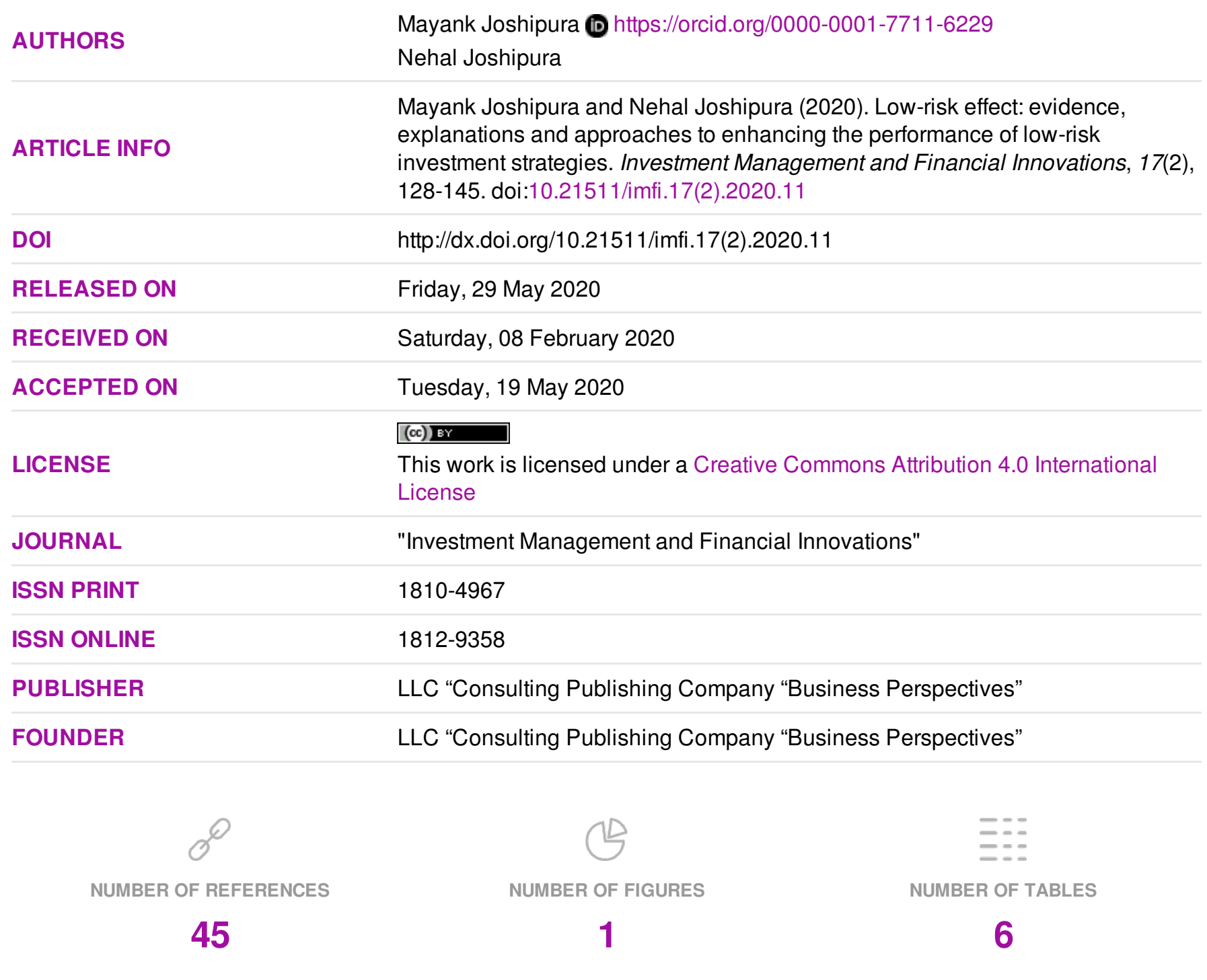

(C) The author(s) 2023. This publication is an open access article. 


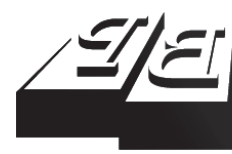

\section{BUSINESS PERSPECTIVES}

LLC "CPC "Business Perspectives" Hryhorii Skovoroda lane, 10, Sumy, 40022, Ukraine www.businessperspectives.org

Received on: $8^{\text {th }}$ of February, 2020 Accepted on: $19^{\text {th }}$ of May, 2020 Published on: $29^{\text {th }}$ of May, 2020
(C) Mayank Joshipura, Nehal Joshipura, 2020

Mayank Joshipura, Ph.D., Professor (Finance), School of Business Management, NMIMS University, Mumbai, India.

Nehal Joshipura, Ph.D., Assistant Professor (Finance), Durgadevi Saraf Institute of Management Studies, Mumbai, India.

\title{
LOW-RISK EFFECT: EVIDENCE, EXPLANATIONS AND APPROACHES TO ENHANCING THE PERFORMANCE OF LOW- RISK INVESTMENT STRATEGIES
}

\begin{abstract}
The authors offer evidence for low-risk effect from the Indian stock market using the top-500 liquid stocks listed on the National Stock Exchange (NSE) of India for the period from January 2004 to December 2018. Finance theory predicts a positive risk-return relationship. However, empirical studies show that low-risk stocks outperform high-risk stocks on a risk-adjusted basis, and it is called lowrisk anomaly or low-risk effect. Persistence of such an anomaly is one of the biggest mysteries in modern finance. The authors find strong evidence in favor of a lowrisk effect with a flat (negative) risk-return relationship based on the simple average (compounded) returns. It is documented that low-risk effect is independent of size, value, and momentum effects, and it is robust after controlling for variables like liquidity and ticket-size of stocks. It is further documented that low-risk effect is a combination of stock and sector level effects, and it cannot be captured fully by concentrated sector exposure. By integrating the momentum effect with the low-volatility effect, the performance of a low-risk investment strategy can be improved both in absolute and risk-adjusted terms. The paper contributed to the body of knowledge by offering evidence for: a) robustness of low-risk effect for liquidity and ticket-size of stocks and sector exposure, b) how one can benefit from combining momentum and low-volatility effects to create a long-only investment strategy that offers higher risk-adjusted and absolute returns than plain vanilla, long-only, low-risk investment strategy.
\end{abstract}

\section{Keywords}

JEL Classification

\section{INTRODUCTION}

Finance theory, pioneered by Modern Portfolio Theory (Markowitz, 1952) and Capital Asset Pricing Model (CAPM) (Sharpe, 1964), advocates a positive relationship between expected return and systematic risk. Capital Asset Pricing Model predicts a positive linear relationship between systematic risk and expected returns of a stock where beta is the measure of risk: a measure of security risk relative to market risk. However, early tests of CAPM (Black, 1972; Fama \& MacBeth, 1973) report positive but flatter than expected risk-return relationship. However, these initial studies challenging the foundation of CAPM were simply brushed aside as an exercise of data mining. Foundation of CAPM took a major hit when Fama and French (1992) showed no relationship between beta and return after controlling for size. Black (1993) reported further flattening of the relationship between beta and return in decades since Black (1972) study sample period. Several studies at the beginning of the $21^{\text {st }}$ century (Clarke, Silva, \& Thorley, 2006; Ang, Hodrick, Xing, \& 
Zhang, 2006, 2009; Blitz \& Vliet, 2007) offer strong evidence for low-risk anomaly and economic and behavioural explanations for the persistence of the low-risk effect. ${ }^{1}$

While the debate about choice of risk measure, portfolio construction model, portfolio weighting scheme, portfolio rebalancing frequency dominated the first phase of research on low-risk effect, the focus of the second phase of research shifted towards explanations for the persistence of low-risk anomaly. The academic debate is still on, but the outperformance of low-risk investment strategies over market-cap weighted benchmark indices across the globe with much lower volatility and drawdowns has caught the attention of the investment management community. The focus of academic research is on looking for factors orthogonal to market-cap weighted benchmark portfolios, explaining the cross-section of equity returns and, hence, requiring a long-short version of factor portfolios. However, most institutional, as well as individual investors, have leverage and short-selling constraints. Even in developed markets, short-selling comes with a high cost. Most institutional investors such as mutual funds, pension funds, insurance companies have long-only mandates and, hence, the long-only leg of the factor portfolio needs to be attractive enough. Analytic Investors Inc. and Robeco launched funds between 2004 to 2006 to exploit low-risk anomaly. While Analytic Investors Inc. launched funds based on minimum variance portfolio construction approach, Robeco launched funds based on volatility ranking-based approach. Both have contributed significantly to the body of literature in the early phase of research before Ang, Hodrick, Xing, and Zhang $(2006,2009)$ caught the attention of academic research community.

The authors intend to address the following key research questions in the Indian context:

1. Is risk-return relationship positive, flat, or negative?

2. How strong is the low-risk effect?

3. Is low-risk effect independent of value, size, and momentum effects?

4. Is low-risk effect a macro effect (sector level) or micro effect (stock level)?

5. Is it possible to integrate long-only low-risk strategy with momentum effect to generate superior risk-adjusted performance?

6. What are the characteristics of long-only low-risk portfolio in Indian markets?

To investigate these questions, the authors use Blitz and Vliet (2007) framework and further develop alternative approaches to enhance the performance of long-only, low-risk investment strategy by adding momentum booster to it while retaining low-risk nature of the strategy. They further analyze portfolio characteristics such as monthly portfolio churn requirement and portfolio concentration for the lowrisk portfolio for the practical implementation of long-only, low-risk investment strategy.

The rest of the paper is organized as follows. Section 1 covers the literature review. Section 2 covers data and methodology. Section 3 documents empirical results, Section 4 offers a discussion on empirical results. Final section offers the conclusion.

\section{LITERATURE REVIEW}

The Capital Asset Pricing Model (CAPM) predicts a linear relationship between systematic risk and expected security returns in which beta is the measure of systematic risk (Sharpe, 1964). However, the early tests of CAPM by Black (1972) and Fama and Macbeth (1973) indicate flatter than expected slope for the security market line. This implies that the risk-return relationship remains positive, but much flatter than expected. Haugen and Heins (1975) were the first to offer evidence for a negative risk-return relationship. Thus, one can trace early evidence of risk-anomaly much before the discovery of return-based anomalies such as size, value, and momentum. At the beginning

1 The terms low-risk anomaly, low-risk effect, and low-volatility effect are used interchangeably throughout this paper. The anomaly explains that low-risk stocks earn a higher return, and high-risk stocks earn a lower return than predicted by the Capital Asset Pricing Model (CAPM). 
of the 1990s, Fama and French (1992) report that beta remains unpriced in the cross-section of the stock universe once controlled for size effect. This implies that beta cannot predict the expected return, and there is no relationship between systematic risk and expected return of a stock.

The real impetus for research on low-risk anomaly came about at the beginning of the $21^{\text {st }}$ century. There is increasing evidence about the presence of low-risk anomaly across the global markets and asset classes beyond equities.

Finally, global financial crisis of 2008 led to large drawdowns across global equity markets and caused significant damage to equity portfolios of many sovereign wealth funds and pension funds. As a result they switched to low-risk investment strategies, that earn equity returns with smaller drawdowns and lower volatility than market portfolio, which resulted into to an explosion in the launch of long-only variants of indices intending to exploit the benefits of a low-risk anomaly. By the end of the first decade of the 21st century, MSCI launched a minimum variance version of the index, whereas S\&P launched an index with a low-volatility version. These facilitated the benchmarking of low-risk investment strategies and the launch of exchange-traded funds (ETF). 25 ETFs are traded in the US markets with asset under management (AUM) worth USD 71 billion (ETF, n.d.). Despite the stellar 10-year bull market in S\&P500, the return of S\&P500 low-volatility index is comparable to that of S\&P500 and is less volatile. This has attracted many individual and institutional money to long-only low-risk investment products. For example, by 2012, UN staff pension fund invested more than USD 500 million in low-volatility equity strategies (P\&I, n.d.).

One can classify the studies on low-risk anomaly based on portfolio construction methods, and choice of risk measures, look-back and holding periods, markets and asset classes and portfolio weighting schemes. As the evidence for low-risk anomaly started mounting on, the focus of research shifted to explaining away the risk anomaly. The recent studies focus on the implementation issues of low-risk investment strategies, decomposing the low-risk anomaly into micro and macro effect "micro and macro effects" instead of "micro and macro effect", and understanding the relationship between low-risk effect and other effects such as size, value, and momentum.

The major contribution to low-risk anomaly literature came through in 2006-2007. Clarke, Silva, and Thorley (2006), Blitz and Vliet (2007), and Ang, Hodrick, Xing, and Zhang (2006) provide evidence for low-risk anomaly using different risk-measures, different look-back periods, and covering the US and other developed markets. Clarke, Silva, and Thorley (2006) use a minimum variance portfolio, whereas Blitz and Vliet (2007) use a ranking-based portfolio construction approach with a three- to five-year look-back period and one-month holding period. Ang, Hodrick, Xing, and Zhang (2006) use the one-month lookback period and daily data to calculate idiosyncratic risk. These studies, despite the difference in methodological choices, offer strong evidence for the low-risk anomaly. Ang, Hodrick, Xing, and Zhang (2009) and Blitz, Pang, and Vliet (2013) provide evidence for major global markets, including emerging markets. Bali and Cakici (2008) argue that the low-risk anomaly is an outcome of the poor performance of penny stocks with lottery-like payoffs, and removing them from the sample restores the positive risk-return relationship. Martellini (2008) reports a positive relationship between risk and return; however, the study has survivorship bias issues. Fu (2009) argues that most studies use backward-looking risk measures, and using forward-looking risk estimation techniques such as the EGARCH model to estimate idiosyncratic risk results in a positive risk-return relationship. Frazzini and Pedersen (2014) develop the Betting-Against-Beta (BAB) factor and established low-risk anomaly as a factor. Among others, Baker, Bradley, and Wurgler (2011), Baker, Bradley, and Taliaferro (2014), Soe (2012), Choueifaty and Coignard (2008), and Leote de Carvalho, Lu, and Moulin (2012) find strong evidence for the lowrisk anomaly.

Increasing evidence on the presence and persistence of low-risk anomaly had started the debate on its explanation. Various studies offer economic and behavioral explanations for the same. One can categorize major economic and behavioral explanations offered to explain the persistence of low-risk effect into various categories: 
a) performance mandate and agency problem;

b) market friction and constraints;

c) behavioural biases and preference for skewness.

Performance mandate and agency problem: Baker, Bradley, and Wurgler (2011) argue that investors with a mandate to outperform a benchmark cannot arbitrage away the low-beta, positive-alpha stocks and show the preference towards high-beta, negative-alpha stocks. This results in the persistence of low-risk anomaly. Brennan, Cheng, and $\mathrm{Li}$ (2012) show that the simultaneous presence of absolute and relative performance-driven investors contributes to flattening of the security market line, and the flattening depends on the proportion of these two types of investors. Beveratos, Bouchaud, Ciliberti, ... and Simon (2017) further confirm that mutual funds tilt towards smaller and high-volatility stocks. Haugen and Baker (2011) argue that call options like compensation structure for investment managers push them to prefer high-volatility portfolios even with slightly lower expected returns. Agarwal, Jiang, and Wen (2018) find that new mutual funds or funds with poor performance in recent past own lottery-like stocks. Hsu, Kudoh, and Yamada (2013) offer evidence that sell-side analysts prefer high-risk stocks, which allows them to take a long shot at fame.

Market friction and constraints: Black (1993) argues that the leverage constraints push investors expected to tilt their investment towards high-risk stocks rather than leverage to increase returns while investing in low-risk stocks or market portfolios. Frazzini and Pedersen (2014) offer further evidence on the same. The BAB factor returns are stronger when funding constraints are tighter. The short-selling constraints contribute to the flattening of the security market line (Miller, 1977).

Behavioral biases: Bali, Cakici, and Whitelaw (2011) attribute low-risk anomaly to investors' preference for lottery-like payoffs, which makes high-risk stocks overvalued, leading to subsequent lower returns. Barber and Odean (2008) explain that representativeness bias and overconfidence make investors choose more volatile stocks as they expect to meet volatility on the right side. Blitz and Vliet (2007) attribute it to a two-stage investment decision-making process, where investors show conservative behavior at the asset allocation stage but then prefer risky stocks at the second stage of the investment process. This is consistent with rational-thinker, irrational-doer version of prospect theory.

The other research branch pertains to decomposing a low-risk anomaly into macro (sector level) and micro (stock level) components. Baker, Bradley, and Taliaferro (2014) decompose the low-risk effect into the country, sector, and stock level effects and show that both micro and macro effects contribute to the low-risk anomaly. Asness, Frazzini, and Pedersen (2014) use a different approach to show that Betting-Against-Beta (BAB) delivers after controlling for industry bets or macro part of the low-risk anomaly.

More recent research concentrates on implementation issues and performance of low-risk investment strategies in various market cycles where researchers focus on comparing and contrasting low-volatility strategies based on the choice of risk measure, look-back period, rebalancing frequency, portfolio weighting scheme, implementation costs, and impact of turnover and other constraints on performance (Asness, Ilmanen, Israel, \& Moskowitz, 2015; Alighanbari, Doole, \& Shankar, 2016; Chow, Hsu, Kuo, \& Li, 2014; Vliet, 2018). Further research focuses on the effect of other factors such as value and momentum on performing low-risk strategies (Blitz, 2016; Garcia-Feijóo, Kochard, Sullivan, \& Wang, 2015).

Blitz and Vliet (2018) report that a simple conservative portfolio construction approach with top100 liquid stocks with low-volatility, high-payout yield, and strong price momentum outperforms not only market portfolio but also most investment strategies based on size, value, momentum, and quality factors. The conservative formula works in the USA, Europe, Japan, and emerging markets. On the other hand, stocks with high volatility, low payout, and weak momentum deliver poor returns.

In India, NSE launched the NSE Low-Volatility 50 Index in November 2012 with base date of December 31, 2003, and the index has delivered superior returns to all major market-cap weighted benchmark indices, including bellwether Nifty 
Index both in absolute and risk-adjusted terms. However, low-volatility investing in India is yet to pick up. There is only one ETF tracking this index launched by ICICI prudential mutual fund in India, and its AUM is too small to mention. That said, the scope for low-volatility investment strategies in India is immense. India has very vibrant primary and secondary equity markets, with more than 5,000 stocks listed on major stock exchanges. India is among the top-10 global equity markets ranked by market-cap. According to the Association of Mutual Funds in India (AMFI), the mutual funds' industry in India has grown more than five-fold in the last 10 years, with a total AUM close to USD 350 billion at the end of December 2019. The pension fund industry in India is in a nascent stage, and there is a great potential for low-cost, low-risk equity products.

The research on low-risk effect in India is at a nascent stage. M. Joshipura and N. Joshipura (2016) report strong evidence for a low-risk effect. Peswani and Joshipura (2019) report evidence of low-risk effect in stocks belongs to different size buckets. However, research on the attractiveness of long-only factor investment strategies, implementation challenges, and integrating size, value, and momentum effects with low-risk effect to enhance the performance of low-risk investment strategies is as at nascent stages in developed markets and a yet-to-start stage in emerging markets like India. The focus is on several under-investigated aspects of low-risk effect in the Indian markets, including testing robustness of low-risk anomaly after controlling for liquidity, ticket-size, and sector exposure; testing practical aspects of long-only, low-risk investment strategy like sector concentration, turnover requirement, sensitivity to alternative weighting scheme, and enhancing the performance of low-risk investment strategy by adding the benefit of momentum effect using alternative approaches.

\section{METHODOLOGY}

At the end of every month, the data on Adjusted monthly closing price, Market capitalization, Price-to-book ratio, Monthly trading turnover, Global Industry Classification Standards (GICS) sector, are collected from Centre for Monitoring
Indian Economy's (CMIE) Prowess Database for all the listed stocks on National Stock Exchange (NSE) of India starting from January 2004 to December 2018. Then the authors sort the stocks based on size measured by market capitalization at the end of every month and then pick the top 500 stocks with available returns for at least 12 months out of the previous 36 months and next 1 month. The adjusted closing price at the end of the month is a proxy for ticket-size and monthly trading turnover as a proxy for liquidity. Momentum for each stock at the end of the month is calculated using the previous 12-month minus 1-month total return. Besides, the authors collect the data for size, value, and momentum factor returns and well as risk-free monthly returns (based on 91-days treasury bills) for the Indian markets from the Indian Institute of Management, Ahmedabad online data library (CMIE, n.d.).

At the end of every month, the authors sort the universe of largest 500 stocks based on the volatility of monthly excess returns (over risk-free returns) of the past three years and construct equalweight risk quintile portfolios. For each quintile portfolio, the excess return for the month following the portfolio construction period is calculated. For the resultant time series, simple annualized average excess return, annualized standard deviation, compounded excess returns (CAGR), Sharpe ratios, ex-ante and ex-post betas, CAPM style one-factor alpha over equal-weight universe portfolio (a proxy for market portfolio) and corresponding $t$-statistics are calculated. Also, tracking errors and skewness for quintile portfolios are calculated.

To test the significance of the difference between the Shape ratio of each risk-quintile portfolio over the market portfolio, Jobson and Korkie (1981) test with Memmel's (2003) correction is used.

The authors calculate CAPM style alpha using the following one-factor regression model:

$$
R_{p, t}-R_{f, t}=\alpha_{p}+\beta_{p, m}\left(R_{m, t}-R_{f, t}\right)+\varepsilon_{p, t},
$$

where $R_{p, t}$ is the return on portfolio $p$ in period $R_{f, t}$ is the risk-free return in the period $t .\left\langle_{p}\right.$ is the alpha of portfolio $p . R_{m, t}$ is market portfolio return in the period $t . \beta_{p, m}$ is the beta of portfolio $p$, and $\varepsilon_{p, t}$ is the 
idiosyncratic return of portfolio $p$ in the period $t$. Equal weight universe is used as proxy for market portfolio.

Fama-French (FF) and Fama-French-Carhart (FFC) models are further deployed to evaluate whether size, value, and momentum factors explain the low-risk anomaly. Small-MinusBig (SMB), Value-Minus-Growth (VMG), and Winner-Minus-Loser (WML) are the proxies for size, value, and momentum factors (Fama \& French, 1992; Carhart, 1997). IIMA online data library is used for monthly factor returns.

$$
\begin{aligned}
& R_{p, t}-R_{f, t}=\alpha_{p}+\beta_{p, m}\left(R_{m, t}-R_{f, t}\right)+ \\
& +\beta_{p, S M B} \cdot R_{S M B}+\beta_{P, V M G} \cdot R_{V M G}+\varepsilon_{p, t}, \\
& R_{p, t}-R_{f, t}=\alpha_{p}+\beta_{p, m}\left(R_{m, t}-R_{f, t}\right)+ \\
& +\beta_{p, S M B} \cdot R_{S M B}+\beta_{P, V M G} \cdot R_{V M G}+ \\
& +\beta_{P, W M L} \cdot R_{W M L}+\varepsilon_{p, t},
\end{aligned}
$$

where $R_{S M B}, R_{V M G}$, and $R_{W M L}$ represent the size, value, and momentum factor premiums, respectively, and $\beta_{p, S M B}, \beta_{p, V M G}$, and $\beta_{p, W M L}$ represent factor loadings of portfolio $p$ on size, value, and momentum factors, respectively.

The study applies bivariate analysis, a strong non-parametric technique using a double sorting approach, to separate low-risk effect from other effects. It is a robust technique and does not get impacted by time-varying exposure of low-risk and high-risk portfolios in three- and four-factor regressions. It allows us to control for the effect of one factor at a time to check the robustness of the low-risk effect. First, one ranks stocks on one of the control factors (size, value, momentum, ticket-size, liquidity) to create quintile portfolios, then one sorts the stocks based on volatility within each control factor quintile portfolio and constructs risk quintile portfolio to represent each quintile of control factor. For example, to control for the size effect, one first sorts stocks based on size to create size quintile portfolios. Next, the stocks are sorted based on volatility within each size quintile portfolios and then $20 \%$ least volatile stocks from every size bucket are combined to construct a lowrisk portfolio representing each size quintile and, hence, controlled for any size exposure. To con- trol for any concentrated sector exposure, low-risk and high-risk portfolios are created to represent each sector and, hence, capture only micro (stock level) low-risk effect while controlling for macro (sector level) effect. The study also reports median sector exposure for low-risk portfolios over the entire period, and the graphically illustrates the time-varying sector exposures to GICS sectors.

A version of the Herfindahl index for low-risk portfolios is used to come up with stock and sector concentration. The Herfindahl index is calculated as the sum of squared weights. Its inverse, $N$ ranges from 1 for a portfolio with only one stock (sector) and $N$ for a portfolio of $N$ equally weighted stocks (sectors). Higher $N$ shows lower concentration risk and vice versa.

Alternative approaches are developed to enhance the performance of low-risk investment strategy by plugging in the benefits of momentum investing to our pure low-risk portfolio. A $2 \times 5$ portfolio construction approach is used. At the end of each month, the stocks to high-momentum or low-momentum sub-universe are first assigned based on their past 12-month minus 1-month returns. Stocks above median momentum returns are assigned to high-momentum universe, and stocks below median momentum are assigned to low-momentum universe. Then risk-quintile portfolios from high-momentum stocks and separately from low-momentum stocks are constructed. The idea is to evaluate whether one can improve the performance of long-only, low-risk portfolio by adding momentum filter.

A scaled volatility measure is further proposed, which scales down the volatility for positive momentum stocks and scales up the volatility for negative momentum stocks. Such scaling helps systematically prefer low-volatility positive momentum stocks, and avoid low-volatility negative momentum stocks. This approach allows us to combine the benefits of risk anomaly and momentum effect while avoiding the stocks with the worst combination of high-risk and negative momentum:

$$
\text { scaled volatlity }=\frac{\text { volatility }}{1+\text { momentum return }},
$$

where momentum return is lesser of momentum return and $100 \%$. 
The horse race is run between three different lowrisk portfolios:

1) pure low-risk portfolio;

2) low-risk portfolio constructed from the high momentum universe; and

3) low-risk portfolio constructed using scaled volatility sorting to compare performance and portfolio characteristics of alternative low-risk investment strategies.

\section{RESULTS}

Table 1 reports the results of univariate analysis for resultant time-series of risk quintile portfolios constructed by sorting stocks on a 36-month look-back period and 1-month holding period. The time-series covers 144 monthly-rebalancing iterations on a rolling forward basis from January 2007 to December 2018. Panel A, reports the annualized simple excess returns, standard deviations, compounded returns, Sharpe ratios, Memmel's statistics for the difference of Sharpe ratio of risk-quintile portfolios over universe portfolio, ex-ante, and ex-post betas, and alphas for risk quintile portfolios sorted on volatility and beta with their corresponding $t$-statistics. Panel B reports the performance of risk quintile portfolios in up and down markets over universe portfolio, maximum drawdown of risk-quintile and universe portfolio, tracking error, and the skewness of risk-quintile portfolios.

Panel A of Table 1 reports the main results of volatility sorted quintile portfolios. Portfolio P1 is the low-risk portfolio and Portfolio P5 is the high-risk portfolio. The simple average annualized excess return for low-risk portfolio (P1), high-risk portfolio (P5), and the equal-weight universe portfolio (EWI) are $13.28 \%, 11.8 \%$, and $13.63 \%$, respectively. While the low-risk portfolio has a higher return than the high-risk portfolio, the return increases as one moves from portfolio P1 to P3 with portfolio $\mathrm{P} 3$ return of $15.06 \%$ and portfolio $\mathrm{P} 4$ return of $14.73 \%$. The compounded return for a lowrisk portfolio, high-risk portfolio and universe are $11.57 \%, 3.02 \%$, and $9.66 \%$, respectively. The long-short portfolio of the long low-risk stocks and short high-risk stocks (L-H) delivers $8.55 \%$ compounded annualized return. The third row of Panel A reports the annualized standard deviation of risk quintile portfolios. The annualized standard deviation of excess returns drops consistently as one moves from P1 to P5. The returns of low-risk portfolio (P1) are $40 \%$ less volatile than market portfolio. The Sharpe ratios of the lowrisk portfolio, high-risk portfolio, and market are

Table 1. Main results (annualized) for quintile portfolios based on historical volatility

\begin{tabular}{|c|c|c|c|c|c|c|}
\hline \multicolumn{7}{|c|}{ Panel A: Quintile portfolios based on historical volatility } \\
\hline Return analysis & Low-risk (P1) & $\mathbf{P 2}$ & P3 & P4 & High-risk (P5) & EWI (universe) \\
\hline Simple return & $13.28 \%$ & $13.29 \%$ & $15.06 \%$ & $14.73 \%$ & $11.80 \%$ & $13.63 \%$ \\
\hline CAGR (excess return) & $11.57 \%$ & $9.87 \%$ & $10.64 \%$ & $8.41 \%$ & $3.02 \%$ & $9.66 \%$ \\
\hline Standard deviation & $18.47 \%$ & $26.16 \%$ & $29.74 \%$ & $35.56 \%$ & $41.89 \%$ & $29.84 \%$ \\
\hline Sharpe ratio & 0.72 & 0.51 & 0.51 & 0.41 & 0.28 & 0.46 \\
\hline Memmel's statistic & 7.05 & 7.94 & 4.06 & -0.40 & -1.60 & 0.00 \\
\hline Ex-ante beta & 0.77 & 0.94 & 1.08 & 1.24 & 1.44 & - \\
\hline Ex-post beta & 0.59 & 0.87 & 0.99 & 1.18 & 1.38 & - \\
\hline Alpha (volatility sorted portfolios) & $5.24 \%$ & $1.50 \%$ & $1.59 \%$ & $-1.37 \%$ & $-6.96 \%$ & - \\
\hline$t$-value & 3.19 & 1.21 & 1.45 & -0.98 & -2.88 & - \\
\hline Alpha (beta sorted portfolios) & $2.73 \%$ & $2.80 \%$ & $1.94 \%$ & $-0.78 \%$ & $-7.44 \%$ & - \\
\hline$t$-value & 1.33 & 1.80 & 1.64 & -0.58 & -2.85 & - \\
\hline \multicolumn{7}{|c|}{ Panel B: Risk analysis of portfolios based on historical volatility } \\
\hline Risk analysis & P1 & $\mathbf{P 2}$ & P3 & P4 & P5 & EWI (universe) \\
\hline Return up (excess return over universe) & $-1.82 \%$ & $-0.72 \%$ & $0.03 \%$ & $0.93 \%$ & $1.58 \%$ & $0.00 \%$ \\
\hline Return down (excess return over universe) & $2.78 \%$ & $1.06 \%$ & $0.25 \%$ & $-1.22 \%$ & $-2.88 \%$ & $0.00 \%$ \\
\hline Max drawdown & $-50.36 \%$ & $-67.39 \%$ & $-72.53 \%$ & $-76.68 \%$ & $-81.17 \%$ & $-70.82 \%$ \\
\hline Tracking error & $13.48 \%$ & $5.83 \%$ & $3.77 \%$ & $7.19 \%$ & $13.94 \%$ & \\
\hline Skewness & -0.42 & 0.34 & 0.55 & 0.78 & 0.79 & 0.49 \\
\hline
\end{tabular}


$0.72,0.28$, and 0.46 , respectively. Memmel's statistics show the significance of the difference between Sharpe ratios of risk quintile portfolios and the market portfolio. The subsequent rows show ex-ante and ex-post betas of risk-quintile portfolios. Both ex-ante and ex-post betas increase in tandem as we move from low-risk to high-risk portfolios. The annualized CAPM style alphas of the low-risk portfolio (P1) and high-risk portfolio (P5) are $5.24 \%(t=3.19)$, and $-6.96 \%(t=-2.88)$, respectively; both are large and economically and statistically significant, albeit with opposite signs. The reported alphas for beta-sorted portfolios show a similar trend.

Panel B of Table 1 performs the risk analysis of the quintile portfolios and decodes the source of the low-risk portfolio's superior long-term returns. The first two rows of panel B show that while low-portfolio underperforms market in up-market periods, it outperforms in down-market periods. The low-risk portfolio drawdown in our sample period is $-50.36 \%$ compared to $-81.17 \%$ for the high-risk portfolio and $-70.82 \%$ for the market portfolio. The last two rows of Panel B of Table 1 report the tracking error and skewness of risk-quintile portfolios. Extreme risk-quintile portfolios P1 and P5 have very high tracking errors of $13.48 \%$ and $13.94 \%$, respectively. The skewness increases as we move from portfolio P1 $(-0.42 \%)$ to $\mathrm{P} 5(0.79 \%)$.
Panel A of Table 2 reports three-factor and four-factor alphas for risk quintile portfolios constructed based on volatility sorting with their corresponding t-statistics. Panel B reports the regression coefficients of market size, value, and momentum factors for low-risk and high-risk portfolios. Together they report the strength of risk effect after controlling for size, value, and momentum effects.

Table 2 reports the results for the three-factor Fama-French (3F) and four-factor Fama-FrenchCarhart (4F) regressions for risk quintile portfolios. Panel A reports $3 \mathrm{~F}$ and $4 \mathrm{~F}$ alphas of risk-quintile portfolios. $3 \mathrm{~F}$ and $4 \mathrm{~F}$ alphas for low-risk portfolio (P1) are 5.3\% $(t=3.23)$ and $3.19 \%(t=2.00)$, respectively, and are economically and statically significant; the same is true for high-risk portfolio (P5). $3 \mathrm{~F}$ and $4 \mathrm{~F}$ alphas for high-risk portfolio (P5) are $-7.11 \%(t=-3.02)$ and $-4.39 \%(t=-1.9)$, respectively, and are economically and statistically significant.

Panel B of Table 2 reports regression coefficients for $3 \mathrm{~F}$ and $4 \mathrm{~F}$ regressions on extreme risk quintile portfolios. The regression coefficients for $3 \mathrm{~F}$ regression for low-risk portfolio (P1) shows that the size factor loading is $0.02(t=0.59)$ and value factor loading is $-0.04(t=-1.7)$, and similar factor loading for $4 \mathrm{~F}$ regression shows that low-risk portfolio (P1) has insignificant size exposure and significant exposure

Table 2. Three-factor (Fama-French) and four-factor (Fama-French-Carhart) style regression analysis for risk quintile portfolios

\begin{tabular}{|c|c|c|c|c|c|}
\hline \multicolumn{6}{|c|}{ Panel A: Three- and four-factor alphas for risk quintile portfolios } \\
\hline Multi factor alphas & P1 (LV) & P2 & P3 & P4 & P5 (HV) \\
\hline Three-factor alpha (annualized) & $5.30 \%$ & $1.51 \%$ & $1.72 \%$ & $-1.42 \%$ & $-7.11 \%$ \\
\hline$t$-value & 3.23 & 1,26 & 1.59 & -1.02 & -3.02 \\
\hline Four-factor alpha (annualized) & $3.19 \%$ & $0.90 \%$ & $0.86 \%$ & $-0.74 \%$ & $-4.39 \%$ \\
\hline$t$-value & 2.00 & 0.79 & 0.95 & -0.51 & -1.90 \\
\hline \multicolumn{6}{|c|}{ Panel B: Three- and four-factor regression coefficient analysis } \\
\hline \multicolumn{6}{|c|}{ Fama-French style regression coefficient for low-risk (LV) and high-risk (HV) portfolios } \\
\hline LV portfolio & Coefficient & $t$-value & HV portfolio & Coefficient & $t$-value \\
\hline Market exposure & 0.60 & 32.72 & Market exposure & 1.34 & 50.92 \\
\hline Size & 0.02 & 0.59 & Size & -0.06 & -1.14 \\
\hline Value & -0.04 & -1.70 & Value & 0.12 & 3.15 \\
\hline \multicolumn{6}{|c|}{ Fama-French-Carhart style regression coefficient for low-risk (LV) and high-risk (HV) portfolios } \\
\hline LV portfolio & Coefficient & $t$-value & HV portfolio & Coefficient & $t$-value \\
\hline Market exposure & 0.64 & 33.50 & Market exposure & 1.29 & 46.47 \\
\hline Size & 0.02 & 0.52 & Size & -0.05 & -1.11 \\
\hline Value & -0.04 & -1.78 & Value & 0.12 & 3.29 \\
\hline Momentum & 0.11 & 4.62 & Momentum & -0.14 & -4.09 \\
\hline
\end{tabular}


Table 3. Double-sorted results

\begin{tabular}{|c|c|c|c|c|c|c|}
\hline Quintile alphas & Low-risk (P1) & $\mathbf{P 2}$ & P3 & P4 & High-risk (P5) & P1-P5 \\
\hline \multicolumn{7}{|c|}{ Panel A: Annualized alpha from double sort on size (market capitalization) and volatility (past 3 years) } \\
\hline Alpha & $5.63 \%$ & $1.63 \%$ & $0.54 \%$ & $-0.27 \%$ & $-7.53 \%$ & $13.16 \%$ \\
\hline$t$-value & 3.34 & 1.18 & 0.54 & -0.21 & -3.18 & 3.46 \\
\hline \multicolumn{7}{|c|}{ Panel B: Annualized alpha from double sort on value (earnings/price) and volatility (past 3 years) } \\
\hline Alpha & $4.71 \%$ & $1.85 \%$ & $1.22 \%$ & $-2.44 \%$ & $-5.34 \%$ & $10.05 \%$ \\
\hline$t$-value & 3.42 & 1.42 & 1.08 & -1.77 & -2.36 & 3.02 \\
\hline \multicolumn{7}{|c|}{$\begin{array}{l}\text { Panel C: Annualized alpha from double sort on momentum } \\
\text { (12-months minus 1-month returns) and volatility (past } 3 \text { years) }\end{array}$} \\
\hline Alpha & $5.29 \%$ & $2.82 \%$ & $1.33 \%$ & $-1.64 \%$ & $-7.81 \%$ & $13.10 \%$ \\
\hline$t$-value & 3.59 & 2.15 & 1.28 & -1.27 & -3.37 & 3.78 \\
\hline \multicolumn{7}{|c|}{ Panel D: Annualized alpha from double sort on turnover (liquidity) and volatility (past 3 years) } \\
\hline Alpha & $5.17 \%$ & $1.33 \%$ & $2.09 \%$ & $-2.24 \%$ & $-6.34 \%$ & $11.51 \%$ \\
\hline$t$-value & 3.26 & 0.98 & 1.97 & -1.75 & -2.73 & 3.19 \\
\hline \multicolumn{7}{|c|}{ Panel E: Annualized alpha from double sort on ticket-size and volatility (past 3 years) } \\
\hline Alpha & $4.68 \%$ & $1.65 \%$ & $1.92 \%$ & $-1.38 \%$ & $-6.86 \%$ & $11.54 \%$ \\
\hline$t$-value & 3.60 & 1.32 & 1.62 & -1.09 & -3.32 & 3.82 \\
\hline
\end{tabular}

to value factor but with a negative sign. The factor loading of the low-risk portfolio on momentum factor is $0.11(t=4.62)$. The analysis of regression coefficients of $3 \mathrm{~F}$ regression for high-risk portfolio (P5) shows that the size factor loading is -0.06 ( $t=$ $-1.14)$ and value factor loading is $0.12(t=3.15)$. The momentum factor loading in the $4 \mathrm{~F}$ regression for the high-risk portfolio is $-0.14(t=-4.17)$.

Table 3 reports the annualized alpha and corresponding $t$-statistics of risk-quintile portfolios after controlling for size, value, and momentum, as well as ticket-size and liquidity. First, quintile portfolios are created by sorting stocks on the control variable and then by sorting on volatility within each quintile portfolio. The risk quintile portfolios are constructed to represent each quintile of control variable. It enables us to separate the alpha of risk-effect after controlling for the effect of other factors, one at a time.

Table 3 reports the results of the double sorting approach to disentangle the low-risk effect from other known effects and factors. The double sort is a robust non-parametric technique that allows testing the robustness of low-risk effect after controlling for other factors, one at a time. It also captures any time-varying exposure of low-risk effect to size, value, and momentum factors, which are assumed to be constant in Fama-French and Fama-French-Carhart regressions.
Panel A of Table 3 reports CAPM style 1-factor alphas for risk-quintile portfolios with their statistical significance. This ensures that each risk-quintile portfolio has stocks representing all size buckets. Such portfolios are controlled for size exposure. One follows the same process to control for value and momentum effects and other variables such as liquidity and unit stock price (ticket size).

The alpha for low-risk portfolio after controlling for size effect is $5.63 \%(t=3.34)$, where the corresponding alpha for high-risk portfolio is $-7.53 \%$ $(t=-3.18)$. The alpha for the low-risk portfolio is large, positive, and statistically significant, whereas the alpha for high-risk portfolio remains large, negative and statistically significant after controlling for size effect. Panels B and C report alphas for risk quintile portfolios controlled for value and momentum factors, respectively, and results are similar. Alphas for low-risk portfolio are large and positive, whereas for high-risk portfolios are large and negative. All are economically and statistically significant.

Panels D and E of Table 3 report alphas for risk quintile portfolios after controlling for liquidity (measured by monthly turnover) and ticket size (measured by unit stock price). The results show large positive alphas for low-risk portfolios and large negative alphas for high-risk portfolios. 
Table 4. Performance of low-risk and high-risk portfolios controlling for sector effect (macro effect)

\begin{tabular}{|c|c|c|}
\hline Sector controlled risk quintile portfolios & Low-risk & High-risk \\
\hline Simple annualized average return & $13.68 \%$ & $13.62 \%$ \\
\hline CAGR & $10.85 \%$ & $7.41 \%$ \\
\hline Standard deviation & $23.80 \%$ & $36.36 \%$ \\
\hline Ex-post beta & 0.78 & 1.21 \\
\hline Alpha (annualized) & $3.01 \%$ & $-2.86 \%$ \\
\hline$t$-value & 2.41 & -2.18 \\
\hline Sharpe ratio & 0.48 & 0.20 \\
\hline Skewness & 0.01 & 0.64 \\
\hline
\end{tabular}

Table 4 reports the performance of sector-neutral low-risk and high-risk portfolios. The stocks are first assigned to one of the GICS sectors, and then stocks within a sector are sorted based on volatility. The low-risk (high-risk) portfolio is constructed from all the stocks with below median (above median) volatility from each sector. The table further reports the ex-post beta, annualized alpha and corresponding $t$-statistics, simple and compounded returns, standard deviation, Sharpe ratio, and skewness for low-risk and highrisk portfolios.

Table 4 reports the results for sector controlled low-risk and high-risk portfolios. The stocks are first assigned to one of eleven GICS sectors, and then within each sector, stocks are assigned to either low or high-risk bucket with median volatility breakpoint. One then creates a low-risk (high-risk) portfolio by pulling together low-risk (high-risk) stocks from each sector to create sector-neutral low-risk (high-risk) portfolios, and controls for sector concentration risk of lowrisk portfolio in this manner. The sector-controlled low-risk portfolio delivers a positive alpha of $3.01 \%(t=2.41)$, whereas high-risk portfolio delivers a negative alpha of $-2.86 \%(t=-2.18)$; both are economically and statistically significant, albeit with opposite signs. The simple annualized average returns for low-risk, high-risk, and market portfolios are $13.68 \%, 13.62 \%$, and $13.63 \%$, with corresponding standard deviations of $23.8 \%, 33.33 \%$, and $29.84 \%$, respectively. There is not much difference in simple returns of sector-neutral low-risk and high-risk portfolios. The difference is large between their compounded returns. CAGR for low-risk and high-risk portfolios is $10.85 \%$ and $7.41 \%$, respectively. The Sharpe ratio of the low-risk portfolio is higher than that of both high-risk portfolio and market portfolio because of its less volatile returns.
Panels A, B, and C of Table 5 report performance statistics including annualized simple return, standard deviation, CAGR, Sharpe ratio, ex-ante, and ex-post betas, and CAPM style alpha for risk-quintile portfolios constructed from high-momentum and low-momentum universe, as well as based on scaled volatility measure.

Table 5 reports the results of risk quintile portfolios constructed from universe of high-momentum and the low-momentum stocks. Panel A of Table 5 reports the results for risk-quintile portfolios from the universe of high-momentum stocks. The high-momentum universe portfolio itself has an alpha of $5.97 \%$ over the market portfolio and a Sharpe ratio of 0.67 compared to 0.46 for the market portfolio. The CAGR, Sharpe ratio and annualized CAPM style alphas for low-risk portfolios are $16.16 \%, 0.99 \%$, and $10.6 \%$, respectively. The corresponding statistics for high-risk portfolios are $8.97 \%, 0.43 \%$, and $-0.04 \%$.

Panel B of Table 5 reports results for the risk-quintile portfolios constructed from the low-momentum universe. The low-momentum universe portfolio itself has a negative alpha of $-5.97 \%$, and a CAGR of just 3.54\% and Sharpe ratio of 0.28, all performance statistics are poor in comparison to market portfolio. All risk-quintile portfolios report negative alphas and lower Sharpe ratios with respect to market portfolio. The worst performing portfolio is the high-risk and low-momentum portfolio. The CAGR, Sharpe ratio, and annualized CAPM style alphas for high-risk portfolio are $-3.69 \%, 0.15 \%$, and $-13.13 \%$, respectively.

Panel C of Table 5 reports the results of low-risk portfolio (P1) and high-risk portfolio (P5) constructed based on volatility scaled by momentum (as explained in the methodology section). The results are very similar to Panel A. Low-risk port- 
Table 5. Performance statistics of momentum blended risk-quintile portfolios

\begin{tabular}{|c|c|c|c|c|c|c|c|}
\hline \multicolumn{8}{|c|}{ Panel A: Risk quintile portfolios from high-momentum universe } \\
\hline $\begin{array}{l}\text { High-momentum risk } \\
\text { quintile portfolios }\end{array}$ & Low-risk & $\mathbf{P 2}$ & P3 & P4 & High-risk & EWI & High-momentum \\
\hline Simple return & $17.79 \%$ & $16.61 \%$ & $20.00 \%$ & $19.45 \%$ & $15.01 \%$ & $13.63 \%$ & $17.77 \%$ \\
\hline Standard deviation & $18.06 \%$ & $24.56 \%$ & $27.52 \%$ & $31.86 \%$ & $34.76 \%$ & $29.84 \%$ & $26.68 \%$ \\
\hline CAGR & $16.16 \%$ & $13.59 \%$ & $16.22 \%$ & $14.38 \%$ & $8.97 \%$ & $9.18 \%$ & $14.21 \%$ \\
\hline Sharpe ratio & 0.99 & 0.68 & 0.73 & 0.61 & 0.43 & 0.46 & 0.67 \\
\hline Ex-ante beta & 0.77 & 0.95 & 1.06 & 1.20 & 1.36 & - & 1.06 \\
\hline Ex-post beta & 0.53 & 0.78 & 0.88 & 1.03 & 1.10 & - & 0.87 \\
\hline Alpha & $10.60 \%$ & $5.98 \%$ & $7.96 \%$ & $5.36 \%$ & $-0.04 \%$ & - & $5.97 \%$ \\
\hline \multicolumn{8}{|c|}{ Panel B: Risk quintile portfolios from low-momentum universe } \\
\hline $\begin{array}{l}\text { Low-momentum risk } \\
\text { quintile portfolios }\end{array}$ & Low-risk & $\mathbf{P 2}$ & P3 & P4 & High-risk & EWI & Low-momentum \\
\hline Simple return & $11.06 \%$ & $11.91 \%$ & $9.15 \%$ & $8.39 \%$ & $6.95 \%$ & $13.63 \%$ & $9.49 \%$ \\
\hline Standard deviation & $25.82 \%$ & $30.21 \%$ & $34.95 \%$ & $38.92 \%$ & $46.13 \%$ & $29.84 \%$ & $34.50 \%$ \\
\hline CAGR & $7.72 \%$ & $7.34 \%$ & $3.04 \%$ & $0.82 \%$ & $-3.69 \%$ & $9.18 \%$ & $3.54 \%$ \\
\hline Sharpe ratio & 0.43 & 0.39 & 0.26 & 0.22 & 0.15 & 0.46 & 0.28 \\
\hline Ex-ante beta & 0.80 & 0.95 & 1.09 & 1.25 & 1.49 & - & 1.12 \\
\hline Ex-post beta & 0.82 & 0.98 & 1.14 & 1.26 & 1.47 & - & 1.13 \\
\hline Alpha & $-0.18 \%$ & $-1.41 \%$ & $-6.37 \%$ & $-8.78 \%$ & $-13.13 \%$ & - & $-5.97 \%$ \\
\hline \multicolumn{8}{|c|}{ Panel C: Risk quintile portfolios from scaled volatility } \\
\hline $\begin{array}{c}\text { Scaled momentum risk } \\
\text { quintile portfolios }\end{array}$ & Low-risk & $\mathbf{P 2}$ & P3 & P4 & High-risk & EWI & \\
\hline Simple return & $20.25 \%$ & $16.32 \%$ & $13.37 \%$ & $11.42 \%$ & $6.80 \%$ & $13.63 \%$ & \\
\hline Standard deviation & $22.81 \%$ & $25.91 \%$ & $28.67 \%$ & $33.83 \%$ & $43.06 \%$ & $29.84 \%$ & \\
\hline CAGR & $17.64 \%$ & $12.96 \%$ & $9.26 \%$ & $5.70 \%$ & $-2.47 \%$ & $9.18 \%$ & \\
\hline Sharpe ratio & 0.89 & 0.63 & 0.47 & 0.34 & 0.16 & 0.46 & \\
\hline Ex-ante beta & 0.89 & 0.99 & 1.07 & 1.17 & 1.34 & - & \\
\hline Ex-post beta & 0.69 & 0.85 & 0.95 & 1.12 & 1.39 & - & \\
\hline Alpha & $10.87 \%$ & $4.73 \%$ & $0.38 \%$ & $-3.81 \%$ & $-12.17 \%$ & - & \\
\hline
\end{tabular}

folio results in a higher CAGR of $17.64 \%$ comparable to $16.16 \%$ in the low-risk, high-momentum portfolio in Panel A. However, with little higher volatility and, hence, lower Sharpe ratio. The alpha of the scaled volatility based low-risk portfolio is $10.87 \%$, similar to $10.6 \%$ of low-risk portfolio filtered for high-momentum. The erosion in the performance of high-risk portfolios is comparable in both approaches.

Table 6 reports sector concentration $N$ score, maximum weight, and the corresponding sector in a given month during the sample period. The table further reports one-way annual churn required to implement the investment strategy like volatility-sorted, beta-sorted, high-momentum, and scaled volatility-sorted low-risk investment portfolios, as well as a broad-based value-weighted market index, NSE 500.
Table 6 and Figures 1a, 1b, 1c, and 1d report the portfolio characteristics of pure and enhanced low-risk strategies discussing sector concentration and the one-way turnover required for these strategies ${ }^{2}$.

The major worry surrounding low-risk investment strategy is that it exposes the portfolio to concentrated exposure to a few sectors such as utility and real estate. Hence, it can create undesirable idiosyncratic sector concentration risk that can lead to sharp portfolio decline. Figure 1 provides the graphical representation of time-varying sector exposure for volatility sorted, beta sorted, scaled volatility sorted, and volatility sorted high-momentum universe, long-only, low-risk portfolios. It is evident from the results of table 6 that the sector $N$ score for all versions of volatility strategies is approximately 7, whereas the $N$ score for NSE 500

2 In addition to results presented here, long-only, low-risk portfolios have been constructed using downside volatility as risk-measure, and inverse-volatility and inverse-beta as portfolio weighting schemes and the results show that low-risk effect is robust to the choice of riskmeasure and portfolio weighting scheme. 
Table 6. Sector exposure statistics and one-way turnover for low-risk investment strategies

\begin{tabular}{|c|c|c|c|c|c|}
\hline Portfolio characteristis & $\begin{array}{c}\text { Volatility } \\
\text { sorted }\end{array}$ & $\begin{array}{c}\text { Beta } \\
\text { sorted }\end{array}$ & $\begin{array}{l}\text { Volatility sorted } \\
\text { high-momentum }\end{array}$ & $\begin{array}{l}\text { Scaled volatility } \\
\text { sorted }\end{array}$ & NSE 500 \\
\hline Sector $N$ & 7.24 & 7.44 & 7.40 & 7.34 & 5.50 \\
\hline Max weight for any sector in a given month & $31 \%$ & $32 \%$ & $21 \%$ & $31 \%$ & $39 \%$ \\
\hline Max weight sector in a given month & Financials & Healthcare & Financials & Financials & Financials \\
\hline Average one-way annualized turnover requirement & $55 \%$ & $63 \%$ & $104 \%$ & $115 \%$ & $15 \%$ \\
\hline
\end{tabular}

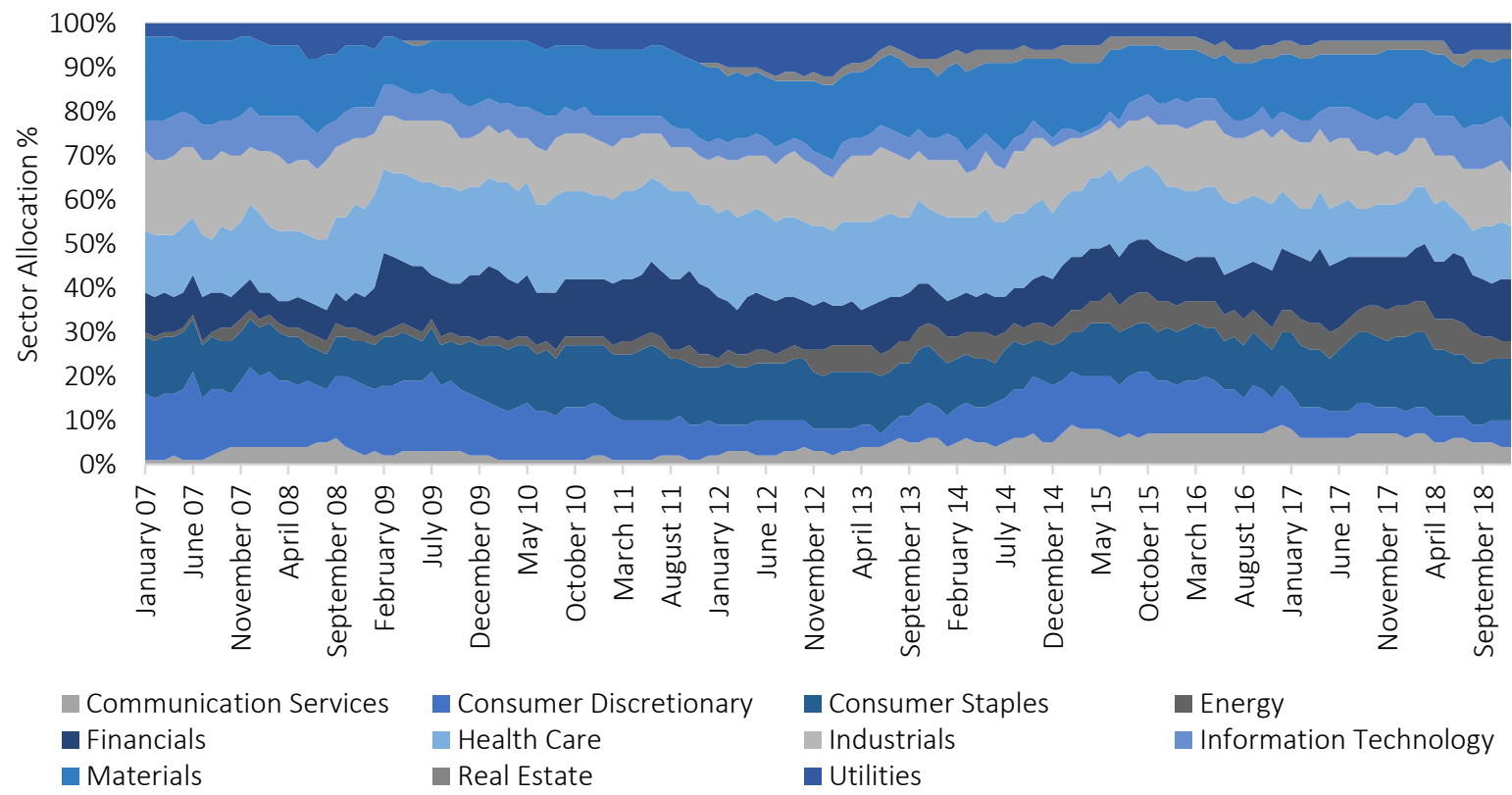

Figure 1a. Volatility sorted low-risk portfolio sector profile

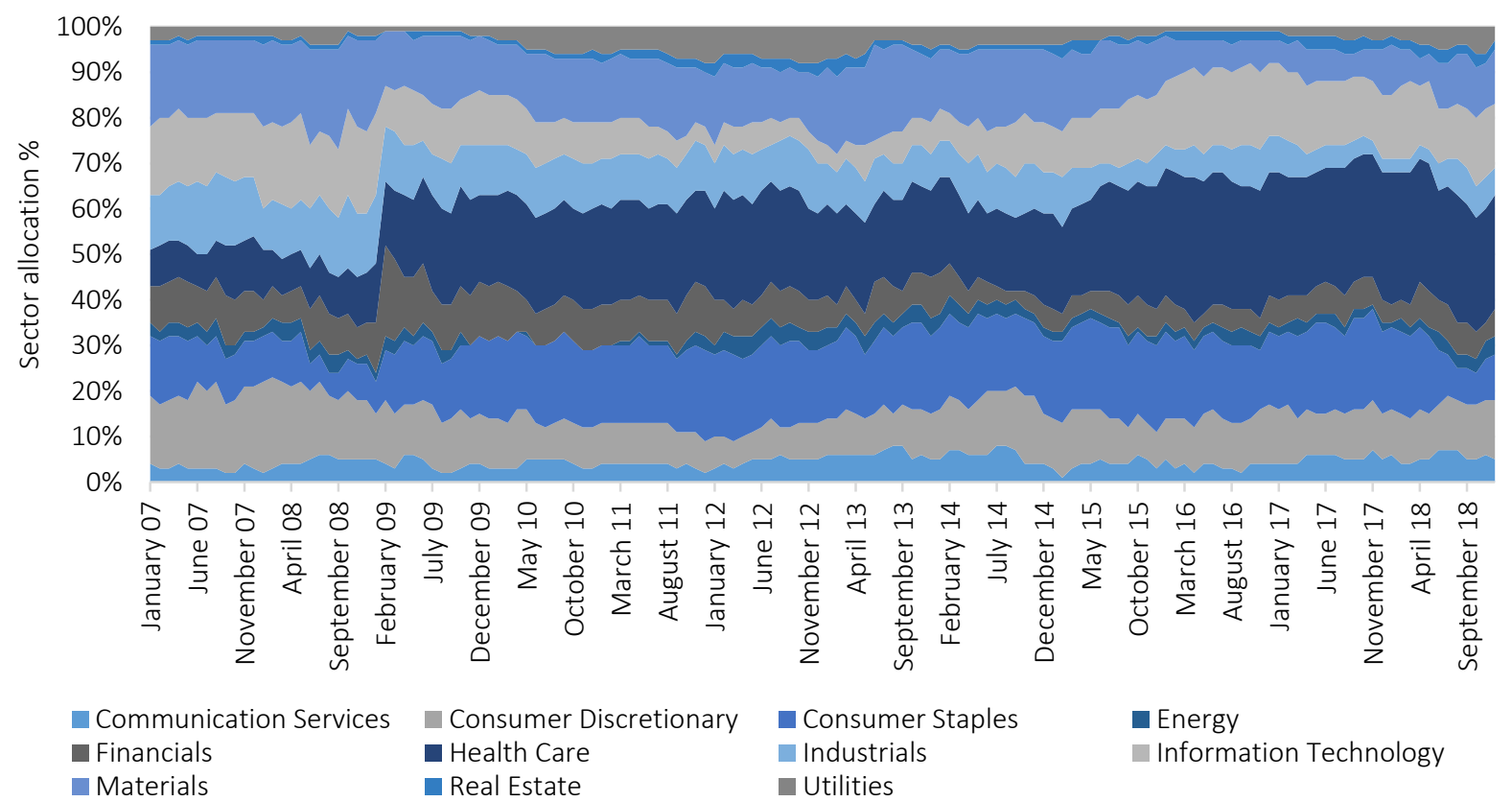

Figure 1b. Beta sorted low-risk portfolio sector profile 


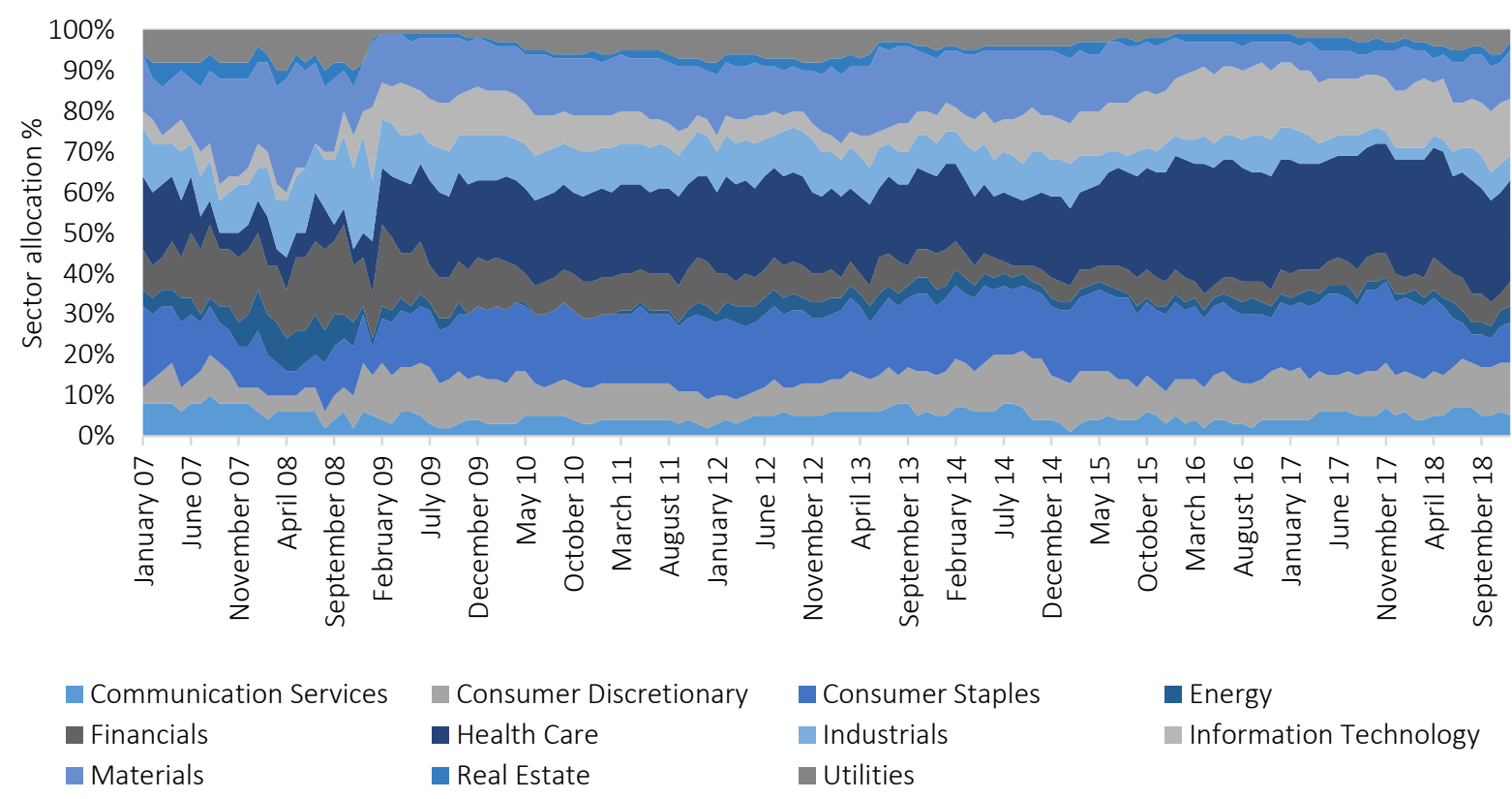

Figure 1c. High-momenturm sorted low-risk portfolio sector profile

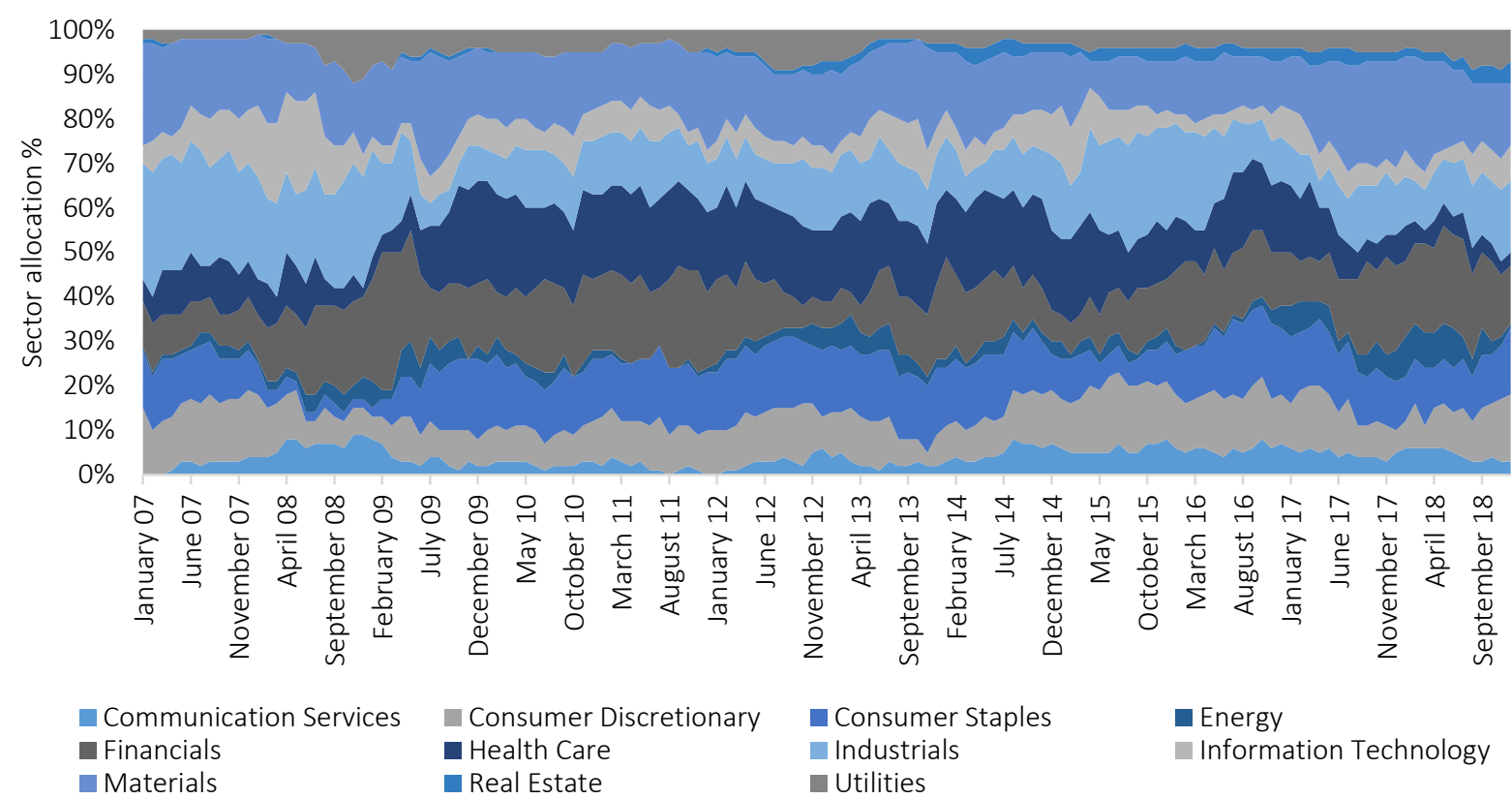

Figure $1 \mathrm{~d}$. Scaled volatility sorted low-risk portfolio sector profile

Note: Figures 1a, 1b, 1c, and $1 \mathrm{~d}$ report time-varying sector profile of low-risk portfolio constructed using volatility sorting, beta sorting, volatility sorting from high-momentum bucket, and scaled-volatility sorting.

Figure 1. Time-varying sector exposure of long-only low-risk portfolios

index, The $N$ score for the most broad-based val- the methodology section. For example, the latest ue-weighted market index is 5.5. The N score of 11 weight of the financial sector in the NSE 500 index means the portfolio represents all the eleven sec- is 37\%, whereas, at no point in the entire study petors equally, and the $N$ score of 1 means the port- riod, any of the low-volatility strategies has sector folio represents only one sector, as explained in exposure over $31 \%$. 


\section{DISCUSSION}

\subsection{Is risk-return relationship positive, flat, or negative?}

It is evident from the results in Panel A of Table 1 that there is no clear relationship between risk and return. The simple annualized excess returns for risk-quantile portfolios initially increase and then decrease. However, the expected positive risk-return relationship turns on its head for compounded returns. The CAGR increases (exception: $2^{\text {nd }}$ to $3^{\text {rd }}$ quintile) as one moves from low-risk portfolio to high-risk portfolio. The standard deviation of risk quintile portfolios increases monotonically as one moves from low-risk to high-risk portfolio, and the volatility of a high-risk portfolio is more than double that of low-risk portfolios. The volatility drag has a large negative impact on high-risk portfolios and leads to negative risk-return relationship on a $\mathrm{CAGR}^{3}$ basis. Both higher return and lower volatility contribute to the highest Sharpe ratio for low-risk portfolio than other risk quantile portfolios and market portfolio. Ex-post beta too monotonically increases as one moves from low-risk to high-risk portfolio, and the same trend is visible for ex-ante beta. This implies that risk is sticky and low-risk portfolios continue to remain low-risk and high-risk portfolios continue to remain high-risk portfolios. The CAPM style alpha for volatility sorted low-risk portfolio is large and positive, whereas it is large and negative for high-risk portfolios. Both are economically and statistically significant and imply a negative risk-return relationship. The CAPM alphas for beta sorted risk-quintile portfolios show similar trends, except alpha for a low-risk portfolio for beta sorted, is not as large and significant as volatility sorted low-risk portfolio.

Low-risk (high-risk) portfolio tends to underperform (outperforms) during rising markets and outperforms (underperforms) during falling markets. However, the low-risk portfolio outperformance in falling markets is much stronger, resulting in a lowrisk portfolio's superior performance. Maximum drawdown is the real measure of risk for any investor and low-risk portfolio has much lower drawdown than both high-risk portfolio and market portfolio and, hence, the success of low-volatility investment strategy lies in winning by losing less ${ }^{4}$. As Baker, Bradley, and Wurgler (2011) reported, the fund managers with relative performance mandate cannot afford large tracking errors, resulting in flattened risk-return relationship. Both low-risk and high-risk portfolios have large tracking errors. It explains low preference for low-risk yet high-tracking error portfolio by fund managers with relative performance mandate. However, such investors should also avoid high-risk portfolio as that too has large tracking error. Perhaps fund managers with call option like compensation structure and investors with a preference for lottery-like payoffs look for high-risk stocks for their positive skewness and avoid low-risk stocks for their negative skewness in return distributions.

\subsection{Is the low-risk effect distinct?}

As reported in Panel A of Table 2, three-factor and four-factor alphas for low-risk (high-risk) portfolios are positive (negative) and economically and statistically significant. This implies that size, value, and momentum cannot explain large positive (negative) residual alpha for low-risk (high-risk) portfolio and, hence, low-risk effect is a distinct effect. Analyzing factor loadings of three-factor and four-factor models reveals that low-risk portfolio has a clear tilt towards growth and winner stocks, whereas high-risk portfolio has a tilt towards value and loser stocks. The growth tilt of low-volatility portfolios is different from the value tilt of low-risk portfolios seen in the developed markets. However, Chow, Hsu, Kuo, and Li (2014) report the growth tilt of low-risk portfolios in the emerging markets. Both low-risk and highrisk portfolios do not show any tilt on size factor, which is due to the selection of the largest 500 listed stocks on NSE.

\subsection{Is low-risk effect robust to time-varying exposure to classic factors, liquidity, and ticket-size exposure?}

The double sorting is a strong non-parametric approach to detangle the low-risk effect from other effects, one at a time. The three-factor and four-fac-

$3 \mathrm{CAGR}=$ Simple return $-0.5 \times$ variance of returns, hence given the level of simple return, higher the variance of returns, lower the CAGR

4 An investment losing $50 \%$ in a given period needs to gain $100 \%$ in the following period to breakeven. In contrast, an investment losing $80 \%$ in a given period needs to gain $400 \%$ in the following period to breakeven. 
tor regressions do not capture any time-varying exposure to size, value, and momentum factors; double sorting tides over that potential limitation as well. The results in Panels A, B, and C of Table 3 establish that large-positive (small-negative) alpha of low-risk (high-risk) portfolio persist after controlling for size, value, and momentum effects. The results in Panels D and E of Table 3 suggest that large-positive (large-negative) alpha of lowrisk (high-risk) portfolio persists after controlling for liquidity and ticket size exposure and, hence, the low-risk effect is truly distinct6 and one cannot fully explain it by systematic exposure of extreme risk-quintile portfolio to liquidity and ticket-size.

\subsection{Is low-risk effect a concentrated macro (sector-level) or micro (stock-level) bet?}

The results from Table 4 give interesting insights. As Baker, Bradley, and Wurgler (2011) reported, low-risk anomaly is a combination of macro (sector level) and micro (stock level) effect, and, hence, portfolio of low-cost sector exchange-traded funds (ETFs) cannot fully capture it. The approach of constructing sector-neutral low (high) risk portfolios controls the volatility effect of the macro (sector level). It captures pure micro (stock level) effect, and significant positive (negative) alpha for sector-neutral low-risk (high-risk) portfolio implies that the low-risk effect is strong and significant after controlling for macro effect, albeit of smaller magnitude.

\subsection{Can one enhance the performance of low-risk investment strategy by adding momentum booster to it?}

The power of adding momentum filter while constructing low-risk investment strategy is visible in results presented in Panels A and B of Table 5. All risk quantile portfolios constructed from universe of high-momentum stocks deliver superior absolute and risk-adjusted performance over corresponding pure risk-quintile portfolios (see Table 1). The high-momentum universe portfolio outperforms low-momentum universe portfolio by a huge margin. The combined benefit of high-momentum and low-risk is visible in the performance of low-risk, high-momentum portfolio. The lowrisk, high-momentum portfolio (Panel A, Table 5) delivers close to $5 \%$ higher CAGR than pure lowrisk portfolio (Panel A, Table 1) without any increase in volatility. A momentum booster is added to pure low-risk investment strategy. On the other hand, the CAGR of low-risk portfolio constructed from low-momentum universe is close to $4 \%$ lower than pure low-risk portfolio and is more volatile. It is observed that the performance of highrisk portfolio further deteriorates when combined with low-momentum. The CAGR for high-risk, low-momentum stocks is negative in about $7 \%$ lower than pure high-risk portfolio. It implies that low-risk, high-momentum stocks are ideal for long only investors, high-risk, low-momentum stocks are the perfect candidates for shorting. The results are similar using alternative approach to add momentum booster to low-risk investment strategy. Low-risk (high-risk) portfolio constructed based on scaled volatility measure delivers superior (inferior) absolute, as well as risk-adjusted returns over pure low-risk (high-risk) portfolio. In sum, notwithstanding the approach, combining momentum effect with low-risk effect results in enhancing performance of low-risk investment strategy.

\subsection{Portfolio characteristics of pure and enhanced low-risk investment strategies}

Table 6 and Figure 1 show that low-risk portfolio is not a concentrated portfolio and the sector concentration of low-risk portfolio is actually lower than the most broad-based value-weighted market index in India, NSE 500. Hence, low-risk portfolio does not lead to any undesirable sector concentration and a resulting tail risk associated with such concentration. Contrary to developed markets where the utilities and real estate dominate minimum variance portfolios, Indian markets have hardly any exposure to utilities and real estate sectors. It is spread across health care, financials, consumer staples, industrials, and materials and has small exposure to real estate and utility sectors.

Turning attention to the monthly portfolio churn requirement, the average one-way monthly portfolio churn required for pure low-risk strategies is about $5 \%$, which means close to $100 \%$ of two-way 
churn for the year. The monthly churn needed for enhanced strategies is close to $10 \%$ and the annual two-way churn of close to $200 \%$. However, as reported by Chow, Hsu, Kuo, and Li (2014) and implemented by MSCI minimum volatility index, independently imposing an explicit limit on annual turnover does not dilute exposure to low-risk effect. Besides, in the case of Indian markets, there are several discount brokerage houses now offering genuine zero brokerage services. The transac- tion costs have come down to a maximum of $0.2 \%$ per transaction, including regulatory charges, security transaction tax, and impact cost. So, even $200 \%$ of an annual churn causes a performance drag of only $0.4 \%$ per annum.

In sum, low-risk investment strategy requires little churning and remains robust after implementing turnover constraints. It is easily implementable with little cost.

\section{CONCLUSION}

In conclusion, strong evidence for low-risk effect with low-risk stocks outperforms high-risk stocks both on an absolute and risk-adjusted basis is found. The effect is more pronounced for compounded returns than simple returns. The low-risk portfolio delivers high-positive alpha, whereas high-risk portfolio delivers high-negative alpha. The low-risk effect remains robust after controlling for size, value, and momentum factors. The low-risk portfolio shows systematic growth-tilt as against value-tilt observed in developed markets. The low-risk anomaly remains robust after controlling for ticket-size and liquidity exposures. The low-risk effect remains robust after controlling for sector exposure, which means the low-risk effect is both macro (sector level) and micro (stock level) effect. Contrary to developed markets, where low-risk portfolios have significant sector concentration towards real estate and utility sectors, low-risk portfolio in Indian markets is less concentrated, and the sector concentration is even less than the broad-based market index. The performance of low-risk investment strategies improves significantly by eliminating low-risk but poor momentum stocks and focusing on constructing low-risk investment strategies that systematically prefer high-momentum stocks. Such improvement in performance is robust to alternative approaches. It is established that while the low-risk effect is universal, the characteristics of low-risk portfolios are different in different markets. The authors further show that the performance of simple low-risk investment strategies can be enhanced by integrating the benefits of momentum effect into low-risk effect.

The paper contributes to the body of literature, especially in the Indian context, in several ways. First, the authors use the top 500 largest stocks in the Indian stock market and, hence, eliminate small and illiquid stocks. Bali and Cakici (2008) attribute extreme negative returns of illiquid and penny stocks to high idiosyncratic risk. Our results show that the low-risk effect is present in the universe of large stocks and remain robust after controlling for ticket-size and liquidity of stocks. Second, the authors reinforce that low-risk effect is robust after controlling for size, value, and momentum factors, and it is a distinct effect. The three-factor and four-factor alphas remain highly significant and positive, and this offers strong evidence against Scherer (2011) who claims that Fama-French factors explain a large part of minimum variance portfolio alpha and the low-risk effect is a mere proxy for the value effect. We report that the low-risk portfolio has growth tilt rather than value tilt, as seen in developed markets. The low-risk effect is present both in emerging and developed markets. It has value tilt in developed markets, whereas growth tilt in emerging markets. The results are similar to Chow, Hsu, Kuo, and Li (2014). Third, the authors show that the low-risk effect is strong after controlling for sector exposure and both macro (sector level) and micro (stock level) effects contribute to the low-risk effect and fourth, the authors show various approaches to integrate benefits of momentum effect into low-risk investment strategy and how it can deliver superior absolute and risk-adjusted returns over pure low-risk investment strategy. It is concluded that the long-only low-risk investment strategy is one of the most prudent ways to generate superior returns over a full market cycle with much smaller drawdowns, and it is possible to enhance the performance of low-risk investment strategy by integrating benefits of momentum effect without compromising its low-risk nature. 


\section{AUTHOR CONTRIBUTIONS}

Conceptualization: Mayank Joshipura, Nehal Joshipura.

Data curation: Mayank Joshipura, Nehal Joshipura.

Formal analysis: Mayank Joshipura, Nehal Joshipura.

Methodology: Mayank Joshipura, Nehal Joshipura.

Software: Nehal Joshipura.

Supervision: Mayank Joshipura.

Validation: Mayank Joshipura, Nehal Joshipura.

Writing - original draft: Mayank Joshipura, Nehal Joshipura.

Writing - review \& editing: Mayank Joshipura, Nehal Joshipura.

\section{REFERENCES}

1. Agarwal, V., Jiang, L., \& Wen, Q. (2018). Why Do Mutual Funds Hold Lottery Stocks? (Research Paper No. 3164692). Georgetown McDonough School of Business. https://doi.org/10.2139/ ssrn.3164692

2. Alighanbari, M., Doole, S., \& Shankar, D. (2016). Designing Low-Volatility Strategies. The Journal of Index Investing, 7(3), 21-33. https://doi.org/10.3905/ jii.2016.7.3.021

3. Ang, A., Hodrick, R. J., Xing, Y., \& Zhang, X. (2006). The cross-section of volatility and expected returns. The Journal of Finance, 61(1), 259-299. https://doi.org/10.1111/j.15406261.2006.00836.x

4. Ang, A., Hodrick, R. J., Xing, Y., \& Zhang, X. (2009). High idiosyncratic volatility and low returns: International and further U.S. evidence. Journal of Financial Economics, 91(1), 1-23. https://doi org/10.1016/j.jfineco.2007.12.005

5. Asness, C. S., Frazzini, A., \& Pedersen, L. H. (2014). Low-Risk Investing without Industry Bets. Financial Analysts Journal, 70(4), 24-41. https://doi.org/10.2469/faj. v70.n4.1

6. Asness, C., Ilmanen, R., Israel, A., \& Moskowitz, T. (2015). Investing with Style. Journal of Investment Management, 13(1), 27-63. Retrieved from https://www.joim. com/investing-with-style/

7. Baker, M., Bradley, B., \& Taliaferro, R. (2014). The Low-Risk Anomaly:
A Decomposition into Micro and Macro Effects. Financial Analysts Journal, 70(2), 43-58. https://doi. org/10.2469/faj.v70.n2.2

8. Baker, M., Bradley, B., \& Wurgler, J. (2011). Benchmarks as Limits to Arbitrage: Understanding the Low-Volatility Anomaly. Financial Analysts Journal, 67(1), 40-54. https://doi.org/10.2469/faj. v67.n1.4

9. Bali, T. G., \& Cakici, N. (2008). Idiosyncratic Volatility and the Cross Section of Expected Returns. Journal of Financial and Quantitative Analysis, 43(1), 29-58. https://doi.org/10.1017/ S002210900000274X

10. Bali, T. G., Cakici, N., \& Whitelaw, R. F. (2011). Maxing out: Stocks as lotteries and the cross-section of expected returns. Journal of Financial Economics, 99(2), 427446. https://doi.org/10.1016/j. jfineco.2010.08.014

11. Barber, B. M., \& Odean, T. (2008). All that glitters: The effect of attention and news on the buying behavior of individual and institutional investors. Review of Financial Studies, 21(2), 785818. https://doi.org/10.1093/rfs/ hhm079

12. Beveratos, A., Bouchaud, J. P., Ciliberti, S., Laloux, L. Lempérière, Y., Potters, M., \& Simon, G. (2017). Deconstructing the low-vol anomaly. The Journal of Portfolio Management, 44(1), 91-103. https://doi.org/10.3905/ jpm.2017.44.1.091
13. Black, F. (1972). Capital Market Equilibrium with Restricted Borrowing. The Journal of Business, 45(3), 444-455. https://doi org/10.1086/295472

14. Black, F. (1993). Beta and Return. The Journal of Portfolio Management, 20(1), 8-18. https:// doi.org/10.3905/jpm.1993.409462

15. Blitz, D. (2016). The Value of Low Volatility. The Journal of Portfolio Management, 42(3), 94-100. https://doi.org/10.3905/ jpm.2016.42.3.094

16. Blitz, D. C., \& Vliet, P. (2007). The volatility effect. The Journal of Portfolio Management, 34(1), 102-113. https://doi.org/10.3905/ jpm.2007.698039

17. Blitz, D., \& Vliet, P. (2018). The Conservative Formula: Quantitative Investing Made Easy. The Journal of Portfolio Management, 44(7), 2438. https://doi.org/10.3905/ jpm.2018.44.7.024

18. Blitz, D., Pang, J., \& Vliet, P. (2013). The volatility effect in emerging markets. Emerging Markets Review, 16(1), 31-45. https://doi.org/10.1016/j.ememar.2013.02.004

19. Brennan, M. J., Cheng, X., \& Li, F. (2012). Agency and Institutional Investment. European Financial Management, 18(1), 1-27. https://doi.org/10.1111/j.1468036X.2011.00596.X

20. Carhart, M. M. (1997). On persistence in mutual fund performance. The Journal of 
Finance, 52(1), 57-82. https://doi. org/10.1111/j.1540-6261.1997. tb03808.x

21. Centre for Monitoring Indian Economy (CMIE). (n.d.). Fama French and Momentum Factors: Data Library for Indian Market. Retrieved from https://web. iima.ac.in/ iffm/Indian-FamaFrench-Momentum/archive/ archive-2015-01-30.php (accessed June 2019).

22. Choueifaty, Y., \& Coignard, Y. (2008). Toward maximum diversification. The Journal of Portfolio Management, 35(1), 40-51. https://doi.org/10.3905/ JPM.2008.35.1.40

23. Chow, T., Hsu, J. C., Kuo, L., \& Li, F. (2014). A Study of LowVolatility Portfolio Construction Methods. The Journal of Portfolio Management, 40(4), 89-105. https://doi.org/10.3905/ jpm.2014.40.4.089

24. Clarke, R., de Silva, H., \& Thorley, S. (2006). Minimum-variance portfolios in the U.S. equity market. The Journal of Portfolio Management, 33(1), 10-24. https:// doi.org/10.3905/jpm.2006.661366

25. Dempsey, M. (2015). The Capital Asset Pricing Model. In Stock Markets, Investments and Corporate Behavior (pp. 11-30). https://doi. org/10.1142/9781783267002_0002

26. Exchange Traded Funds (ETF). (n.d.). Official website. Retrieved from https://www.etf.com/

27. Fama, E. F., \& French, K. R. (1992). The Cross-Section of Expected Stock Returns. The Journal of Finance, 47(2), 427. https://doi. org/10.2307/2329112

28. Fama, E. F., \& MacBeth, J. D. (1973). Risk, Return, and Equilibrium: Empirical Tests. Journal of Political Economy, 81(3), 607-636. https://doi. org/10.1086/260061

29. Frazzini, A., \& Pedersen, L. H. (2014). Betting against beta. Journal of Financial Economics, 111(1), 1-25. https://doi. org/10.1016/j.jfineco.2013.10.005

30. Fu, F. (2009). Idiosyncratic risk and the cross-section of expected stock returns. Journal of Financial Economics, 91(1), 24-37. https://doi.org/10.1016/j. jfineco.2008.02.003

31. Garcia-Feijóo, L., Kochard, L., Sullivan, R. N., \& Wang, P. (2015). Low-Volatility Cycles: The Influence of Valuation and Momentum on Low-Volatility Portfolios. Financial Analysts Journal, 71(3), 47-60. https://doi. org/10.2469/faj.v71.n3.2

32. Hsu, J. C., Kudoh, H., \& Yamada, T. (2013). When Sell-Side Analysts Meet High-Volatility Stocks: An Alternative Explanation for the Low-Volatility Puzzle. Journal of Investment Management, 11(2), 28-46. Retrieved from https:// www.researchaffiliates.com/ documents/2013-JOIM-SellSideAnalysts.pdf

33. Jobson, J. D., \& Korkie, B. M. (1981). Performance Hypothesis Testing with the Sharpe and Treynor Measures. The Journal of Finance, 36(4), 889-908. https:// doi.org/10.1111/j.1540-6261.1981. tb04891.x

34. Joshipura, M., \& Joshipura, N. (2016). The Volatility Effect: Evidence from India. Applied Finance Letters, 5(1), 12-27. https://doi.org/10.24135/afl. v5i1.32

35. Leote de Carvalho, R., Lu, X., \& Moulin, P. (2012). Demystifying Equity Risk-Based Strategies: A Simple Alpha plus Beta Description. The Journal of Portfolio Management, 38(3), 56-70. https://doi.org/10.3905/ jpm.2012.38.3.056

36. Markowitz, H. (1952). Portfolio Selection. The Journal of Finance, 7(1), 77-91. https://doi. org/10.2307/2975974

37. Martellini, L. (2008). Toward the Design of Better Equity Benchmarks. The Journal of Portfolio Management, 34(4), 34-41. https://doi.org/10.3905/ jpm.2008.709978

38. Memmel, C. (2003). Performance Hypothesis Testing with the Sharpe Ratio. Finance Letters, 1(1), 21-23. Retrieved from https://ssrn. com/abstract $=412588$
39. Miller, E. M. (1977). Risk, Uncertainty, and Divergence of Opinion. The Journal of Finance, 32(4), 1151-1168. https://doi. org/10.1111/j.1540-6261.1977. tb03317.x

40. Pensions \& Investments (P\&I) (n.d.). Official website. Retrieved from https://www.pionline.com/

41. Peswani, S., \& Joshipura, M. (2019). The volatility effect across size buckets: evidence from the Indian stock market. Investment Management and Financial Innovations, 16(3), 62-75. https://doi.org/10.21511/ imfi.16(3).2019.07

42. Scherer, B. (2011). A note on the returns from minimum variance investing. Journal of Empirical Finance, 18(4), 652-660. https://doi.org/10.1016/j.jempfin.2011.06.001

43. Sharpe, W. F. (1964). Capital Asset Prices: A Theory of Market Equilibrium under Conditions of Risk. The Journal of Finance, 19(3), 425-442. https://doi. org/10.2307/2977928

44. Soe, A. M. (2012). Low-Volatility Portfolio Construction: Ranking Versus Optimization. The Journal of Index Investing, 3(3), 63-73. https://doi.org/10.3905/ jii.2012.3.3.063

45. van Vliet, P. (2018). Low Volatility Needs Little Trading. The Journal of Portfolio Management, 44(3), 33-42. https://doi.org/10.3905/ jpm.2018.44.3.033 